\title{
Adenosine deaminase activity in tuberculous pericarditis
}

\author{
JOSÉ M MARTINEZ-VAZQUEZ, ESTEBAN RIBERA, IMMA OCAÑA, \\ ROSA M SEGURA, RAMON SERRAT, JAIME SAGRISTA
}

From the Department of Internal Medicine, Service of Biochemistry, and Service of Cardiology, Ciudad Sanitaria Valle de Hebron, Universidad Autonoma, Barcelona, Spain

Adenosine deaminase (Enzymes Commission No 3.5.4.4) is an enzyme capable of catalysing the catabolism of purine bases. Previous studies have shown that this enzyme may be useful in recognition of a tuberculous aetiology of pleural, peritoneal, or meningeal effusions. ${ }^{1-5}$ Adenosine deaminase assay is a simple, sensitive, and specific diagnostic procedure in these conditions but its use in diagnosis of tuberculous pericarditis has not previously been reported.

\section{Methods and results}

We studied the activity of adenosine deaminase in the pericardial fluid of 56 patients who were included in a systematic prospective protocol, similar to that reported previously. ${ }^{23}$ Patients were grouped according to the definite diagnosis, as follows: group I-three patients with tuberculous pericarditis confirmed by bacterial culture and by histopathological examination; group II-10 patients with acute idiopathic pericarditis and negative results in viral serological tests; group III-16 patients with neoplastic pericarditis confirmed by cytological or histological tests; group IV-11 patients with miscellaneous conditions (uraemic pericarditis 7 cases, radiation pericarditis 1 case, lupus pericarditis 2 cases, Dressler's syndrome 1 case); group V-16 control individuals without pericardial disease from whom pericardial fluid was obtained during cardiac surgery. We also studied simultaneously the serum adenosine deaminase levels in 48 of the 56 patients.

The determination of adenosine deaminase activity in the pericardial fluid and serum was carried out by the method of Galanti and Giusti ${ }^{6}$. This is a colorimetric method based on measurement of the formation of ammonia, which is produced when adenosine deaminase acts on an excess of adenosine.

Individual results of adenosine deaminase activity in the pericardial fluid are given in the figure. In patients with tuberculous pericarditis the mean enzyme activity was 96.8 (SD 1.54) U/1, much higher than that for all other patients. In group II the mean (SD) value was $9 \cdot 39(5 \cdot 16)$, in group III $11.75(5.48)$, in group IV $12.38(6.76)$, and in group V 3.96 $(6 \cdot 33) \mathrm{U} / 1$. There was no correlation between serum activity of adenosine deaminase and enzyme activity in pericardial fluid (Spearman test).

Address for reprint requests: Professor JM Martinez-Vazquez, Facultad de Medicina, Universidad Autonoma de Barcelona, Paseo Valle de Hebron s/n, 08035 Barcelona, Spain.

Accepted 21 January 1986

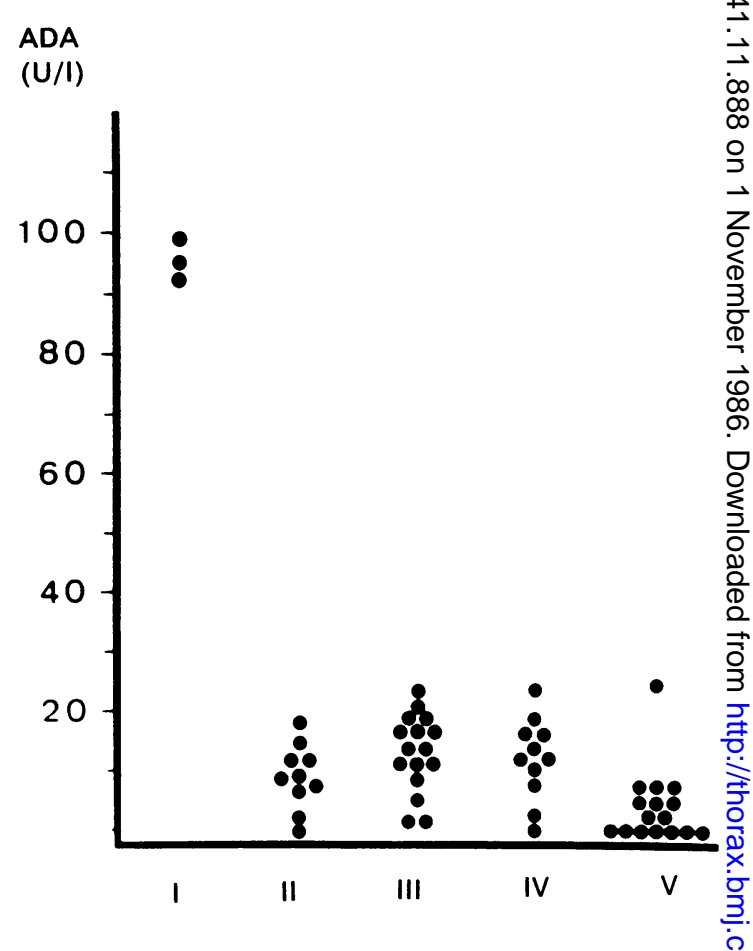

Adenosine deaminase activity $(A D A)$ in pericardial fluid of individual patients in groups $I-V$.

\section{Discussion}

Tuberculous pericarditis is now an uncommon condition in $\mathrm{N}$ Western countries, but there is considerable urgency in establishing the correct diagnosis so that appropriate treat- $\sigma$ ment can be started. Early diagnosis is, however, difficult and cultures of the pericardial fluid for Mycobacterium $\stackrel{0}{\subset}$ tuberculosis are often negative, so that more invasive pro- $\mathbb{\Phi}$ cedures such as open pericardial biopsy may be necessary.

In a previous study we confirmed the almost selective increase in adenosine deaminase activity in tuberculous pleural effusion, with a sensitivity of 1 and a specificity of $0.97 .^{2}$ In the group of 48 patients with tuberculous pleurisy 
the mean (SD) enzyme activity was $92.4(29.4) \mathrm{U} / \mathrm{l}$, whereas for other aetiological groups the mean activity varied from 2 to $20 \mathrm{U} / 1$. In patients with tuberculous peritonitis the results were similar. ${ }^{3}$ The adenosine deaminase activity of our patients with tuberculous pericarditis is similar to the mean values found in our previous study of tuberculous pleural or peritoneal effusions. The mean enzyme activity in the pericardial fluid of the other groups of subjects was also similar to that of patients in the earlier studies with non-tuberculous pleuroperitonitis.

Adenosine deaminase is an enzyme detected primarily in T lymphocytes. In a previous study, ${ }^{2}$ however, we found no relationship between adenosine deaminase activity and the number of $\mathrm{T}$ cells in pleural fluid; possibly the selective increase of adenosine deaminase activity in tuberculous effusions depends on the degree of stimulation of T lymphocytes.

The specific increase in adenosine deaminase activity in our three patients with tuberculous pericarditis in comparison with results in the remaining 53 non-tuberculous patients suggests that assay of this enzyme in pericardial fluid could be of great value in the early diagnosis of tuber- culous pericarditis, but studies on more patients with pericardial tuberculous infection are needed.

\section{References}

I Piras MA, Gakis C, Budroni M, Andreoni G. Adenosine deaminase activity in pleural effusions: an aid to differential diagnosis. Br Med J 1978;ii:1751-2.

2 Ocaña I, Martinez-Vazquez JM, Segura RM, Fernandez de Sevilla T, Capdevila JA. Adenosine deaminase in pleural fluids: test for diagnosis of tuberculous pleural effusion. Chest 1983;84:51-3.

3 Martinez-Vazquez JM, Ocaña I, Ribera E, et al. Diagnóstico temprano de la tuberculosis pleuroperitoneal mediante la determinación de adenosina desaminasa. Med Clin (Barcelona) 1984;83:578-80.

4 Petersson T, Ojala K, Weber TH. Adenosine deaminase in the diagnosis of pleural effusion. Acta Med Scand 1984;215:299-304.

5 Piras MA, Gakis C. Cerebrospinal fluid adenosine deaminase activity in tuberculous meningitis. Enzyme 1973;14:314-7.

6 Giusti G. Adenosine deaminase. In: Bergmeyer HV, ed. Methods of enzymatic analysis. New York: Academic Press, 1974:1092-9. 